\title{
Discurso e formação de professor: documentos que instituem sentidos para práticas profissionais
}

\author{
Discourse and teacher formation: \\ documents which establish meanings to professional practice
}

Vera Lucia de Albuquerque SANT'ANNA*

Universidade do Estado do Rio de Janeiro (UERJ)

\begin{abstract}
RESUMO: O objetivo deste artigo é apresentar compreensões de sentidos de formação de professor e seus possíveis desdobramentos no que concerne à valorização dos saberes advindos da experiência, que circulam no campo dos discursos da prescrição, em particular no Parecer CNE/CP $n^{\circ}$ 9/2001, que trata dos fundamentos para a formulação das Resoluções CNE/CP $n^{\circ} 1$ e $n^{\circ} 2$ de 2002. Essas, por sua vez, vão instituir as diretrizes curriculares nacionais para formação de professores da educação básica, em nível superior, curso de licenciatura, graduação plena. Esta proposta compreende a análise de textos relacionados ao trabalho/formação como um lugar de encontros conceituais, conceitos esses advindos de estudos ergológicos voltados para o trabalho (SCHWARTZ, 1992), da análise do discurso e seu enfoque sobre etos e heterogeneidade enunciativa (AUTHIER-REVUZ, 1998; MAINGUENEAU, 2005; ROMUALDO, 2008).
\end{abstract}

PALAVRAS-CHAVE: Formação de professor. Reforma da licenciatura. Perspectiva discursiva. Linguagem e trabalho.

ABSTRACT: The aim of this paper is to present different ways of understanding the meanings of teacher formation and their possible outcomes concerning the increase in value of knowledge resulting from the experience in the area of discourses of prescription, specially on the Report $\mathrm{CNE} / \mathrm{CP}$ nbr 9/2001 which discuss the formulation bases of Resolution CNE/CP nbr 1 and nbr 2 of 2002. These legal documents will establish the national curriculum guidelines for the formation of basic education teachers, in higher education, teaching certification, bachelor degree. The proposal includes the analysis of texts related to work/formation as a place where concepts meet, concepts which arise from Ergologic studies oriented to work (SCHWARTZ, 1992), from Discourse Analysis and its focus on ethos and enunciative heterogeneity (AUTHIER-REVUZ, 1998; MAINGUENEAU, 2005; ROMUALDO, 2008).

KEYWORDS: Teacher formation. Teaching certification reform. Discursive Perspective. Language and work.

\section{Introdução}

Os homens fazem a sua própria história, mas não a fazem segundo a sua livre vontade, em circunstâncias escolhidas por eles próprios, mas nas circunstâncias imediatamente encontradas, dadas e transmitidas pelo passado.

(Marx, O 18 brumário de Luis Bonaparte, p.207)

\footnotetext{
* Doutorado em Linguística Aplicada aos Estudos da Linguagem. Professora da Universidade do Estado do Rio de Janeiro (UERJ), Instituto de Letras e Programa de Pós-Graduação em Letras, área de concentração Mestrado em Linguística (Práticas de Linguagem e Discursividade). Rio de Janeiro - RJ - Brasil. E-mail: verasantanna@terra.com.br.
} 
Discurso é conceito já revisitado por muitos autores, em diferentes textos, com propósitos muito particulares. Desde os que se dedicam a conceituações generalizantes apresentados em forma de verbetes, que podem ser apropriadas para situações específicas, até os que usam a palavra "discurso" sem grandes pretensões de redefini-la. No caso deste livro, cada de um nós que aqui publicamos nossas reflexões, tratamos de mostrar nossa inclusão numa certa comunidade discursiva: nos aproxima a ideia do sujeito que agrega a combinação de muitas vozes, que ultrapassa os limites da coincidência entre "o eu e minha fala", que não crê nessa monofonia como forma de existência possível no mundo histórico e social que partilhamos. O princípio da simultaneidade nos faz copartícipes da vida, a coexistência nos obriga à interação, ao diálogo multidirecionado - às outras pessoas, às outras palavras já ditas e por dizer: "As relações dialógicas [...] penetra[m] toda a linguagem humana e todas as relações e manifestações da vida humana, em suma tudo o que tem sentido e importância" (BAKHTIN, 1997, p.42). A esse entendimento de sujeito polifônico, inapelavelmente dialógico, soma-se a ideia de que a palavra pronunciada constrói seu espaço e tempo de circulação, ao mesmo tempo que se abre a ser compreendida, sempre parcialmente, já que os sentidos surgem da relação com o interlocutor, particular e historicamente situado.

Cada vez que se produz uma situação de interação, os sentidos possíveis dos discursos se retomam, se relançam, se alternam/alteram: "a ideia é interindividual e intersubjetiva, a esfera da sua existência não é a consciência individual, mas a comunicação dialogada entre as consciências" (BAKHTIN, 1997 p.87). E isso nos importa porque aqui ideia e discurso são semelhantes, porque o discurso, tal como uma ideia, exige uma compreensão, requer uma resposta mesmo que ainda não pronunciada. São posicionamentos discursivos que constroem sentidos, que personificam toda enunciação, no sentido de que esta é sempre construída por um enunciador que no e pelo seu modo de enunciar constrói para si mesmo uma imagem a ser captada no movimento dialógico da interlocução. Personificar, aqui, não está associado a enunciador como indivíduo, mas como instância enunciativa.

Este texto, portanto, ao se propor a analisar, a partir dessa compreensão de discurso, documentos emitidos por órgão federal que prescrevem práticas de formação profissional de professor, considera que a produção desses textos aponta traços da instância enunciativa que permitem buscar respostas para a seguinte indagação: o que propõem pareceres e leis federais que reformam a Licenciatura, no que concerne ao entendimento do que seja formação para o trabalho de professor do ensino básico?

Um estudo discursivo de documentos de âmbito nacional, que definem os traços a serem valorizados na formação do professor no Brasil, é uma das etapas necessárias para identificar as necessidades, atacar as dificuldades e valorizar os acertos do ensino no nosso país. Afinal, para ser professor no Brasil há uma legislação nacional que define parâmetros para a formação e a atuação profissional, que não pode ser desconhecida por aqueles que formam ou atuam nessa área.

O objetivo da reflexão que aqui se expõe é identificar a constituição de sentidos de formação de professor, e seus possíveis desdobramentos no que concerne à valorização dos saberes advindos da experiência, que circulam no campo dos discursos da prescrição, em particular no Parecer $\mathrm{CNE} / \mathrm{CP} \mathrm{n}^{\circ}$ 9/2001, que trata dos fundamentos para a formulação das Resoluções CNE/CP n ${ }^{\circ} 1$ e $\mathrm{n}^{\mathrm{o}} 2$ de 2002, que, por sua vez, vão instituir as diretrizes curriculares nacionais para formação de professores da educação básica, em nível superior, curso de licenciatura, graduação plena. Esta proposta compreende a análise de textos relacionados ao trabalho/formação como um lugar de encontros conceituais, conceitos esses advindos de estudos ergológicos voltados para o trabalho (SCHWARTZ, 1992), da 
análise do discurso e seu enfoque sobre etos e heterogeneidade enunciativa (AUTHIERREVUZ, 1998; MAINGUENEAU, 2005; ROMUALDO, 2008).

Como consequência do fundamento teórico que justifica este capítulo, registramos que as reformas não acontecem, elas são construídas por discursos e práticas, que têm desdobramentos, que exigem tomadas de posição no dia-a-dia da atividade do formador de professores. As formas de ação incluem os espaços legais, as brechas na organização institucional, a prática dos insatisfeitos que propõem alternativas, mesmo quando não há apoio oficial. A força de imposição do discurso oficial o torna politicamente dominante, assim, são as pesquisas e os embates que podem apontar caminhos para as dificuldades que essa imposição forçosamente cria. Este capítulo, então, é uma tentativa de colaborar na compreensão do que estabelecem os textos oficiais sobre o que é/deve ser a formação para a profissão de professor.

\section{A prescrição sobre o trabalho: a formação do professor}

Trazer para discussão documentos prescritivos da formação para o trabalho de professor, na perspectiva que articula linguagem e trabalho, nos obriga a enfocar esses textos como parte das normas antecedentes, isto é, tudo que preexiste à atividade e a organiza, mas que só se concretiza na e pelas renormalizações efetuadas no momento da atividade do trabalhador. Como nos auxilia Schwartz, é a partir desse entendimento ergológico do que seja a realização de uma atividade - lugar do encontro entre normas e renormalizações, atravessadas por valores - que observamos a produção discursiva de uma manifestação do campo dos discursos prescritivos. Portanto, estudar um Parecer do Conselho Nacional de Educação (CNE) nesse enfoque é observá-lo, ao mesmo tempo, como constituído de um caráter demonstrativo no qual se expõem fundamentos filosóficos para a elaboração de uma norma - a Resolução -, e como demonstração se apresenta como se não houvesse uma relação entre enunciador e co-enunciador; e um caráter argumentativo, que implica a existência dessa relação e, por isso, requer a busca de convencimento do interlocutor a fim de que este observe que a proposta demonstrada é justa e adequada. A combinação desses traços nos remete a questões relacionadas à ideia de memória discursiva - isso fala antes, em outro lugar -, quer como verdades indiscutíveis (porque demonstradas eficazmente), quer como ideias a serem defendidas (porque fundamentadas em argumentos válidos). Portanto, o estudo de textos prescritivos no que se refere à formação/trabalho do professor inclui, necessariamente, a observação de uma gama muito ampla de produções. Nosso recorte se dá a partir da Constituição de 1988, ponto de partida para a elaboração da LDB no 9394/1996, responsável pelo desencadeamento de um conjunto (i)numerável de pareceres e resoluções do $\mathrm{CNE}$, bem como de propostas oriundas do próprio MEC (por exemplo, parâmetros, orientações, programa de seleção de livros, ...), voltadas para as reformulações exigidas pela LDB e pelos desdobramentos daí advindos. Entre eles, nosso foco de interesse é o Parecer $\mathrm{CNE} / \mathrm{CP} \mathrm{n}^{\circ} 9 / 2001^{1}$, de $08 / 05 / 2001$, porque é dele que resultam as Resoluções que tratam da reforma das Licenciaturas.

Antes de tratar do parecer em análise, há alguns traços do gênero de discurso que precisam ser trazidos para que possamos discutir de que modo o etos constituído e as heterogeneidades identificadas participam da construção de subjetividades atribuídas aos que formam e são formados professores. O objetivo de um parecer é apresentar ponto de vista técnico sobre um tema; em geral, dá os fundamentos filosóficos e legais daquilo que

\footnotetext{
${ }^{1} \mathrm{O}$ seu item 3.6, alínea c, que trata da definição do estágio curricular, foi alterado pelo Parecer $\mathrm{CNE} / \mathrm{CP} \mathrm{n}^{\circ}$ 27 , de $02 / 10 / 2001$.
} 
poderá vir a tornar-se uma ação com força coercitiva, manifestada, por exemplo, em forma de lei. Aquele que enuncia tem seu pronunciamento tratado como técnico, o que lhe atribui traços de um enunciador reconhecido como competente para tratar de certo assunto. Quanto ao modo de organização textual, observando-se alguns pareceres, é possível detectar que regularmente se compõem de um relato fundamentado sobre o assunto, do voto do parecerista/relator e da decisão da comissão ou autoridade, à qual se submete obrigatoriamente o parecer. $\mathrm{O}$ enunciador de um parecer não legisla, sua apreciação funciona como subsídio para tomada de decisões de outra instância que decide sobre a adequação e pertinência do parecer. Portanto, um parecer não faria parte do conjunto das prescrições stricto sensu da formação/trabalho, já que não há nele uma injunção claramente exposta e direcionada ao professor em formação - o par interlocutivo seria formado pelo parecerista e os membros de um colegiado. Ainda assim, pretendemos inclúí-lo nesse espaço discursivo das prescrições voltadas para a formação do professor porque o diálogo com outro gênero, a legislação que dele decorre e o define como seu discurso constituinte, ${ }^{2}$ promove interdiscursividades antecipadoras do campo da normalização que a lei registrará. ${ }^{3}$ A combinação de traços da demonstração e da argumentação vai ajudar a melhor compreender esse modo particular de ser injuntivo, tomando como base que a injunção pode advir do conceito, que prescreve tanto ou mais do que a definição de um modo de fazer.

O Parecer CNE/CP no 9/2001, composto por setenta páginas, está dividido em quatro partes: (1) Relatório - contém breve histórico das reuniões realizadas pelo grupo responsável pelo assunto, uma análise do panorama da educação no Brasil nos anos 80 e 90, e a proposta (pp. 7-28) para as diretrizes curriculares para a formação de professores da educação básica; (2) Voto da relatora (p. 28-67), que retoma vários itens da proposta e os detalha; (3) Decisão do plenário; (4) Voto em separado. Para este capítulo, limitamos a análise a itens do Relatório e do Voto da relatora, no que tange à discussão sobre formação e experiência, a saber: (a) um pequeno trecho do início do Relatório e os seus itens 3.2.4 Tratamento restrito da atuação profissional e 3.2.5 - Concepção restrita de prática; (b) e do Voto da relatora, o item 2.3.5 Conhecimentos advindos da experiência. Como parte da análise, faremos uma aproximação aos artigos da Resolução CNE/CP $n^{0}$ 1/2002 que registram a discussão em forma de texto legislador.

\title{
2 Etos, interdiscursividade e sentidos de formação e experiência
}

$\mathrm{Na}$ entrada do texto do Parecer, observamos que o enunciador nos informa sobre os parceiros responsabilizados pela existência da proposta:

\section{(1) Fragmento 1}

\begin{abstract}
Introdução
O documento que hoje constitui esta Proposta de Diretrizes para a Formação de Professores da Educação Básica, em cursos de nível superior, foi submetido à apreciação da comunidade educacional em cinco audiências públicas regionais, uma reunião institucional, uma reunião técnica e uma audiência pública nacional, nas datas, locais e com público especificados a seguir [...]. (BRASIL, 2001, p.2)
\end{abstract}

\footnotetext{
2 Discurso constituinte pode ser compreendido como aquele que funda o seu direito à fala e, como consequência, ganha força estruturadora de outros discursos (MAINGUENEAU, 2005).

${ }^{3}$ Bakhtin (1995) nos auxilia a compreender a interação verbal como o diálogo entre um enunciador, seu interlocutor e todos os outros discursos com os quais dialoga, os existentes e os que estão por vir - a palavra lança-se para o futuro.
} 
Não é preciso muito esforço para observar que o enunciador inicia seu processo de demonstração de modo duplamente impessoal: no nível discursivo - formas de apagamento do enunciador - e no nível empírico - o texto é resultado da participação de um conjunto de pessoas. Se por um lado, ressalta-se o caráter democrático e representativo do documento produzido, garantindo ao enunciador um etos de pessoa honesta, democrata, portanto, não autoritária; por outro, aponta para o espaço de responsabilidade ocupado por essas outras vozes, que se deverão fazer sentir no interior do documento. Isso remete àquele que teve de orquestrar discordâncias, foi submetido a pressões, interesses; ou seja, compõe um etos de esforço e altruísmo - aqui, dizemos como Romualdo (2008, p.216) "há duas dificuldades [na apreensão do etos] um etos qualquer pode ser percebido como uma vaga impressão, um 'não sei o quê'; a outra é a busca da materialidade em que a vaga impressão se apoia, dando expressão ao etos" - é esse caminho que pretendemos seguir: identificar marcas ainda que sutis, que sustentem nosso aporte. Portanto, o Parecer técnico e impessoal - ultrapassa os limites do texto demonstrativo: é resultado de uma gestão discursiva, traço predominante na constituição do etos do enunciador - aqui fala o dito em outros lugares e que o enunciador precisou gerir para democraticamente incluir múltiplos entendimentos sobre o assunto. Não cabe registro desse histórico no texto da legislação (BRASIL, 2002), porém, há referência direta ao Parecer como "peça indispensável" para a compreensão do que propõe a lei.

Observemos os fragmentos a seguir. Em primeiro lugar, tratamos do Relatório. Considerando o modo inicial de apresentação do etos, espera-se que no parecer manifestem-se vozes em embate, a fim de que o enunciador possa indicar o caminho a ser seguido - a demonstração -, bem como o porquê de fazê-lo - a argumentação. Assim, o Relatório é entendido como parte do parecer destinado a ser um apresentador generalista, no qual não se espera localizar marca da opinião clara, tal como talvez coubesse ao espaço do voto do relator. Apesar desse traço discursivo, a polêmica entre quem enuncia e os discursos trazidos como opositores, sempre lidos a partir das grades semânticas desse enunciador, processo esse que caracteriza o fenômeno da interincompreensão (MAINGUENEAU, 2005), pode ser observada:

\title{
(2) Fragmento 2
}

\author{
RELATÓRIO \\ 3.2.4 Tratamento restrito da atuação profissional \\ A formação de professores fica, geralmente, restrita à sua preparação para a \\ regência de classe, não tratando das demais dimensões da atuação profissional \\ como sua participação no projeto educativo da escola, seu relacionamento com \\ alunos e com a comunidade. Ficam ausentes também, frequentemente, as \\ discussões sobre as temáticas relacionadas mais propriamente ao sistema \\ educacional e à atuação dos professores, restringindo a vivência de natureza \\ profissional.(BRASIL, 2001, p.22.)
}

Ao apresentar como uma constatação o modo como vem sendo efetivada a formação do professor - A formação de professores fica, geralmente, restrita à sua preparação para a regência de classe -, o enunciador do Relatório assume que o que existe não atende a todas as dimensões de uma situação de trabalho docente: há vozes que dão sustentação a essa forma de compreender a formação para o trabalho (o ressaltado no trecho pelo sublinhado) e é contra elas que se coloca o Relatório. Formar todo e qualquer professor para o trabalho deve incluir preparar para dar aulas, participar do projeto da escola, relacionar-se com a comunidade, discutir o sistema educacional. Nesse fragmento, o enunciador traz repercussão de embates históricos dos movimentos sindicais, que 
continuam pautados como reivindicações não atendidas: a situação de trabalho do professor não se define exclusivamente pela sua ação em sala de aula. Isso tem desdobramentos trabalhistas: não é possível remunerar no contrato somente essa carga horária, é preciso incluir horas para as demais atividades que compõem essa situação de trabalho. Matéria, portanto, que escapa à norma que regula a Licenciatura, como, então, se registraria esse entendimento de situação de trabalho na Resolução CNE/CP $n^{0} 1 / 2002$ ? Podemos verificar que no seu Art. $6^{\circ}$, quando trata do projeto político pedagógico da instituição formadora, faz referência a que esse deve registrar competências, entre outras, referentes a "valores inspiradores da sociedade democrática", "à compreensão do papel social da escola". Mas isso é pouco. Permanecem em aberto quais seriam os modos de preparar um professor para que fizesse respeitar esse direito trabalhista, ainda que o primeiro passo seja efetivamente conceitual: o que vem a ser o trabalho do professor?

Verifiquemos o fragmento 3:

\title{
(3) Fragmento 3
}

\begin{abstract}
RELATÓRIO
3.2.5 Concepção restrita de prática (p.22)

Nos cursos de formação de professores, a concepção dominante, conforme já mencionada, segmenta o curso em dois pólos isolados entre si: um caracteriza o trabalho na sala de aula e o outro, caracteriza as atividades de estágio. O primeiro pólo supervaloriza os conhecimentos teóricos, acadêmicos, desprezando as práticas como importante fonte de conteúdos da formação. Existe uma visão aplicacionista das teorias. O segundo pólo supervaloriza o fazer pedagógico, [...]. Uma concepção de prática mais como componente curricular implica vê-la como uma dimensão do conhecimento que tanto está presente nos cursos de formação, nos momentos em que se trabalha na reflexão sobre a atividade profissional, como durante o estágio, nos momentos em que se exercita a atividade profissional. [...]

Outro problema refere-se à organização do tempo dos estágios, geralmente curtos e pontuais: [...]. Além disso, é completamente inadequado que a ida dos professores às escolas aconteça somente na etapa final de sua formação, pois isso não possibilita que haja tempo suficiente para abordar as diferentes dimensões do trabalho de professor, nem permite um processo progressivo de aprendizado.

A ideia a ser superada, enfim, é a de que o estágio é o espaço reservado à prática, enquanto, na sala de aula se dá conta da teoria.(BRASIL, 2001, p. 22)
\end{abstract}

Nesse item, referencia-se a dissociação teoria-prática. A crítica vem por meio de um conjunto de argumentos que se baseiam na negativa daquilo que existe - a concepção dominante, que supervaloriza um dos pólos - e propõe que a prática precisa ser tratada como "dimensão de produção de conhecimento", isto é, seu planejamento e execução dependem do modo como o curso de formação organiza essa dimensão. A crítica ao tempo e o momento atribuído aos estágios tem como argumento o fato de que é preciso "acompanhar a rotina do trabalho pedagógico durante um período contínuo". Observe-se que o etos vem se constituindo a partir da oposição ao que existe, por meio de negações polêmicas, ${ }^{4}$ ou outras marcas que integram o campo do negar um pressuposto, para lançar-se como falando de outro lugar que, se não é o dominante, é aquele que oferece alternativas para a compreensão de prática e de teoria (ver trechos sublinhados). $\mathrm{Na}$ Resolução $\mathrm{CNE} / \mathrm{CP} \mathrm{n}^{\circ} 1$, essa preocupação aparece em vários momentos (Art. $3^{\circ}$, item II; Art.11\% ; Art. $13^{\circ}$ ), comentamos: Art. $12^{\circ}$ - registra nos três parágrafos que "a prática, na matriz curricular, não poderá ficar reduzida a um espaço isolado", deverá estar presente

\footnotetext{
${ }^{4}$ Conceituação atribuída a Ducrot (1987), em seus estudos sobre a negação como marca de heterogeneidade enunciativa, ao permitir observar num enunciado a presença de duas enunciações.
} 
desde o início e as disciplinas curriculares e pedagógicas terão a sua dimensão prática; Art. $14^{\circ}$ - aponta que cada instituição deve construir seus projetos abrangendo as dimensões teóricas e práticas, entre outros itens a serem considerados. Observam-se duas questões: (1) o traço marcante do etos do enunciador do Parecer se reduplica na Resolução (a negação), o que não seria usual já que a regra, em geral, é elaborada de modo direto (faça-se tal coisa); (2) a dissociação teoria-prática recebeu um tratamento intensivo no texto regulador. O modo como o problema é exposto no Parecer e na Resolução merece uma observação: nenhum dos dois documentos refere-se ao afastamento que existe, necessária e obrigatoriamente, entre o que se planeja e o que se executa, isto é, entre normas antecedentes e renormalizações, parciais e contingenciais, porque comportam valores em confronto.

Em estudo sobre a reforma das Licenciaturas, Garcia (2008, p.13) chama a atenção para o fato de que "a matriz curricular proposta pelo CNE, ao distribuir o tempo da formação docente e caracterizar os componentes dos saberes que constituem essa matriz, introduz uma clara dicotomia entre teoria e prática na formação dos professores" , conforme pode ser observado no quadro a seguir, exatamente ao contrário do que pregava o Parecer:

\begin{tabular}{|c|c|}
\hline Natureza das atividades & Horas \\
\hline Conteúdos curriculares de natureza científico-cultural da área específica & 1800 \\
\hline Práticas como componentes curriculares & 400 \\
\hline Estágios Supervisionados & 400 \\
\hline Atividades acadêmico-científico-culturais & 200 \\
\hline Total & 2800 \\
\hline
\end{tabular}

(Fonte: BRASIL. Resolução nº 2, 2002, p. 1)

Constata-se, então, que se manteve de forma clara a clássica divisão entre os conhecimentos tradicionalmente tratados como "científico-culturais", para os quais se destinaram 1800 horas mais as 200 horas das atividades também "científico-culturais", enquanto práticas e estágios foram tratados como exclusivamente ligados à formação profissional, e receberam 800 horas. Manteve-se a divisão que há tempos vem sendo condenada por estudiosos preocupados com a formação do professor: por um lado, conteúdos científico-culturais dissociados da formação profissional de professor, por outro, disciplinas a serem interpretadas como de forte cunho profissional, deixando em aberto múltiplas compreensões do que poderiam vir a ser os programas para essas disciplinas práticas e a natureza e modo de existir dos estágios.

Compartilhamos da visão de Garcia (2008, p. 13) quando, ao estudar a reforma da Licenciatura implementada em sua Universidade, constata que

A leitura dessa normativa [a Resolução CNE/CP n $\left.{ }^{\circ} 1 / 2002\right]$ pelos filtros de um forte pragmatismo que caracteriza a prática pedagógica e o ensino, de uma tradição curricular que espacializa em tempos e lugares distintos a teoria e a prática, e da valorização de uma ciência de caráter experimentalista, reinscreveu essa separação no desenho curricular da maioria das Licenciaturas analisadas. (GARCIA, 2008, p. 13) 
A forte discussão sobre teoria e prática que o Parecer traz como fundamento da divisão das horas da matriz proposta acaba por não ultrapassar a visão reducionista dessa relação, na forma como se registrou na lei, a Resolução, a distribuição das horas e na concepção dos blocos de disciplinas. A compreensão que Schwartz nos oferece sobre a atividade humana na situação de trabalho, como simultaneamente objetiva, porque prescrita (portanto, idealizada, teorizada), e subjetiva, porque realizada segundo as condições pessoais e históricas possíveis (portanto, materializada, vivida na experiência), permite afirmar que estamos ainda distantes de compreender o trabalho como uma dinâmica, uma interseção de valores. $E$ isso não garantiu uma identificação do perfil profissional do magistério como um compromisso de todo o contingente de disciplinas oferecidas ao graduando. Ao reinscrever a separação teoria-prática, o documento recai na visão de que uma teoria poderia existir sem uma prática e esta, por sua vez, não dependeria daquela para existir. Contudo, a relação de unidade entre teoria e prática, e não de uniformidade, permite pensar numa certa autonomia da teoria, porque ela pode anteciparse às necessidades práticas, ainda que não se transforme automaticamente em prática; mas exige que se perceba que a prática funciona como o critério de verdade e de finalidade para uma teoria, porque a prática não existe sem ingredientes teóricos. Sánchez Vázquez (2007) dedica ao par teoria-prática uma discussão filosófica muito ampla e aprofundada. Recorrendo a seus ensinamentos, podemos afirmar que uma prática transformadora (a práxis) - e aqui podemos incluir a atividade de trabalho do professor - é sempre necessária e obrigatoriamente uma atividade teórico-prática. É, portanto, compreender uma atividade para transformá-la - mote dos estudos ergológicos - a finalidade básica da formação profissional: quanto mais se conhece sobre ela, melhor se pode formar para ela, incorporando as obrigatórias renormalizações entre teorias e práticas.

No fragmento 4, que corresponde ao Voto da Relatora, vamos observar de modo mais claro a referência aos saberes da experiência:

\section{(4) Fragmento 4}

\section{VOTO DA RELATORA}

2.3.6 Conhecimento advindo da experiência

O que está designado aqui como conhecimento advindo da experiência é, como o nome já diz, o conhecimento construído "na" e "pela" experiência. Na verdade, o que se pretende com este âmbito é dar destaque à natureza e à forma com que esse conhecimento é constituído pelo sujeito. É um tipo de conhecimento que não pode ser construído de outra forma senão na prática profissional e de modo algum pode ser substituído pelo conhecimento "sobre" esta prática. Saber - e aprender - um conceito, ou uma teoria é muito diferente de saber - e aprender a exercer um trabalho. Trata-se, portanto, de aprender a "ser" professor.

[...] A competência profissional do professor é, justamente, sua capacidade de criar soluções apropriadas a cada uma das diferentes situações complexas e singulares que enfrenta.

Assim, este âmbito de conhecimento está relacionado às práticas próprias da atividade de professor e às múltiplas competências que as compõem e deve ser valorizado em si mesmo. Entretanto, é preciso deixar claro que o conhecimento experiencial pode ser enriquecido quando articulado a uma reflexão sistemática. Constrói-se, assim, em conexão com o conhecimento teórico, na medida em que é preciso usá-lo para refletir sobre a experiência, interpretá-la, atribuir- lhe significado. (BRASIL, 2001, p. 49)

O voto da relatora retoma a discussão teoria-prática a partir de outros critérios, o da enunciação por conceitos: saberes instituídos, para dizer como Schwartz (1997), mobilizam o interlocutor no sentido de ajudá-lo a aceitar parâmetros e a definir direcionamentos sobre 
a forma de pensar. Enuncia-se para convencer: Saber - e aprender - um conceito, ou uma teoria é muito diferente de saber - e aprender - a exercer um trabalho. Trata-se, portanto, de aprender a "ser" professor. No Voto da relatora, a experiência é resultado da atividade submetida a situações singulares, ao mesmo tempo, requer conexão com o conhecimento teórico. Contudo, quando afirma que é preciso deixar claro que o conhecimento experiencial pode ser enriquecido quando articulado a uma reflexão sistemática, a relatora se afasta da ideia que defendemos: não há possibilidade de haver conhecimento baseado na experiência que já não esteja em algum grau associado a fundamentos teóricos. Para nós, as antecipações nomalizadoras do trabalho impõem rumos, regras, prescrições, sempre fundamentados num certo modo de conceber o trabalho, ainda que estas antecipações possam ser completamente modificadas, alteradas, anuladas pela renormalização inerente à atividade.

Esse voto da relatora materializa-se na Resolução CNE/CP $n^{0} 1 / 2002$, por meio do Art. $6^{\circ}$, dividido em seis itens, cujo parágrafo $3^{\circ}$, do item VI, vai tratar da definição de conhecimentos exigidos para a constituição de competências; entre esses se encontra o "conhecimento advindo da experiência", sem nenhuma explicação. Como cada instituição de ensino vai compreender experiência e poder fazer essa incorporação a seu currículo? Apontamos essa como mais uma das dificuldades de colocação em prática da matriz curricular proposta pelo CNE para as Licenciaturas no Brasil. ${ }^{5}$

\section{Breves comentários finais}

Ao se propor a estudar uma legislação como manifestação da ordem do discurso, recusamos qualquer atribuição de força ao documento por ele mesmo ou aos que apresentam criticas a ele. Nosso propósito é exercitar o que até agora pregamos, a unidade sempre instável e inexorável entre teoria e a prática: os estudos do discurso nos apontam caminhos teóricos para compreender práticas discursivas de legalidade, porque políticas brasileiras de formação de professor oriundas da esfera federal, logo, obrigatórias para todas as instituições responsáveis pela formação desse profissional, vão definir perfis gerais a serem efetivados de forma local: o que cada universidade/faculdade/instituto quer para o seu licenciando? Que traços de subjetividade serão ressaltados? E, em particular, para o licenciando em Letras? Cabe a nós, professores formadores de professores, discutir modos de articular (ou não) essa prescrição com nossas atuações e necessidades locais.

E, ainda, é preciso registrar que os embates entre os poderes internos a unidades e departamentos por mais horas/disciplinas deixam no desenho da matriz curricular institucional suas marcas. Porém, a conquista da reforma da licenciatura de uma instituição deve(ria) ser a construção de uma consciência de grupo, porque é preciso gerar entre nós formadores de professores uma ideia de comunidade - que não pode ser considerada apenas por ser composta de pessoas que atuam no mesmo espaço de relações sociais. Uma comunidade discursiva que se sustenta por inserir-se em formação(ções) discursiva(s) semelhantes: aquelas que garantem uma defesa da formação profissional que atenda às necessidades históricas, mas lembremos da epígrafe deste capítulo, porque se os homens fazem a sua própria história, mas não a fazem segundo a sua livre vontade, em circunstâncias escolhidas por eles próprios, mas nas circunstâncias imediatamente encontradas, dadas e transmitidas pelo passado, nosso papel como formadores de

\footnotetext{
${ }^{5}$ Participamos em evento da ALAB no ano de 2009, numa mesa de trabalhos coordenados cujo foco era exatamente como as instituições estavam compreendendo as disciplinas "práticas"; o que se observou foi que há uma disparidade brutal entre as formas de compreender seu objetivo, fundamento e razão de existir para a formação do professor.
} 
professores e pesquisadores é garantir que as teorias sejam capazes de antecipar práticas que desafiem novos modos de enfrentar as dificuldades da atuação profissional na educação básica, e que acompanhem as práticas na sua dinâmica de produção de novas ideias: as renormalizações em diálogo com as normalizações, mediado pelos valores trazidos por cada um dos componentes dessa comunidade. Sem pretensão de universalidades, nem homogeneidades, porém com clareza de que um projeto próprio de professor de ensino básico precisa incorporar uma visão de trabalho que permita lidar com a opacidade das relações humanas.

\section{REFERÊNCIAS}

AUTHIER-REVUZ, J. Palavras incertas: as não-coincidências do dizer. Tradução Claudia R. Castellanos et al. Campinas: Ed. Unicamp, 1998.

BAKTHIN, M. Problemas da poética de Dostoiésvki. 2. ed. Tradução Paulo Bezerra. Rio de Janeiro: Forense Universitária, 1997.

BRASIL. Conselho Nacional de Educação. Parecer CNE/CP 009/2001, de 8 de maio de 2001. Diretrizes Curriculares Nacionais para a Formação de Professores da Educação Básica, em nível superior, curso de licenciatura, de graduação plena. Publicado no Diário Oficial da União, Brasília, DF, 18 de jan. 2002. seção 1, p. 31. Disponível em: $<$ http://portal.mec.gov.br/cne/arquivos/pdf/009.pdf>. Acesso em: 15 fev. 2008.

BRASIL. Conselho Nacional de Educação. Resolução CNE/CP 1, de 18 de fevereiro de 2002. Institui Diretrizes Curriculares Nacionais para a Formação de Professores da Educação Básica, em nível superior, curso de licenciatura, de graduação plena. Disponível em: <http://portal.mec.gov.br/cne/arquivos/pdf/rcp01_02.pdf>. Acesso em: 15 fev. 2008.

BRASIL. Conselho Nacional de Educação. Resolução CNE/CP 2, de 19 de fevereiro de 2002. Diário Oficial da União, Brasília, DF, 4 de mar de 2002, seção 1, p. 9. Institui a duração e a carga horária dos cursos de licenciatura, de graduação plena, de formação de professores da Educação Básica em nível superior. Disponível em: $<$ http://portal.mec.gov.br/cne/arquivos/pdf/CP022002.pdf>. Acesso em: 14 fev. 2008.

BRASIL. Conselho Nacional de Educação. Resolução CNE/CP 2, de 27 de agosto de 2004. Disponível em: <http://portal.mec.gov.br/cne/arquivos/pdf/CP022004.pdf>. Acesso: em: 15 fev. 2008.

DURÃO, P. Técnica de Parecer: Como fazer um dictamen jurídico. Curitiba: Juruá, 2007.

GARCIA, M. M. A. Texto e contexto: a reforma em cursos de licenciatura na Universidade Federal de Pelotas (UFPEL). In: [Anais da] Reunião Anual da ANPEd, 31., 2008, Caxambú,. Disponível em: http://www.anped.org.br/reunioes/31ra/1trabalho/GT12-4192-Res.pdf. Acess:em: 15 jul.2010.

MAIngueneAU, D. Gênese dos discursos. Tradução Sírio Possenti. Curitiba: Criar, 2005.

ROMUALDO, J. A. Etos e discurso científico. In: MOTTA, Salgado (org.) Etos discursivo. São Paulo: Contexto, 2008, p.213-221.

SÁNCHEZ VÁZQUEZ, A. Filosofia da práxis. São Paulo: Expressão Popular, [1967] 2007. 
SANT'ANNA, V. L. A.; SOUZA-E-SILVA, M. C. P. Trabalho e prescrição: aproximações ao problema a partir dos estudos da linguagem. Revista Matraga, Rio de Janeiro, v. 14, n. 20, p.77-99, jan/jun. 2007.

SCHWARTZ, Y. (Org.) Reconnaissances du travail: pour une approche ergologique. Paris: Presses Universitaires de France, 1997.

Recebido em fevereiro de 2013.

Aprovado em abril de 2013. 